\title{
Mating system analysis in Pinus leucodermis Ant.: detection of self-fertilization in natural populations
}

\author{
M. MORGANTE, G. G. VENDRAMIN* \& A. M. OLIVIERI \\ Istituto di Produzione Vegetale, Universitá di Udine, Via Fagagna 209, 1-33100 Udine, *Istituto Miglioramento Genetico \\ Piante Forestali, C.N.R., Via San Bonaventura 13, 1-50145 Firenze, Italy
}

\begin{abstract}
The mating system was analysed in two natural populations of Pinus leucodermis Ant., a narrow ranged and relic species. The amount of outcrossing was estimated by assaying four enzyme loci. An efficient multilocus model was used, which allows the joint estimation of outcrossing rate and pollen allele frequencies for individual trees. The estimated multilocus outcrossing rates were 0.765 and 0.840 in the two populations. Both regression of individual pollen allele frequencies on the additive value of the maternal genotypes and outcrossing rates estimated with the unique allele method revealed that these low outcrossing rate estimates were not merely determined by mating among relatives, but reflected significant levels of selfing. They are especially significant, if compared with those observed in other conifers, which are almost complete outbreeders. The estimated selfing rate may be an upper limit because it was obtained by analysing non-germinated seeds. The presence of such a selfing level in this species could have important implications for seed production, as it seems that strong selection acts against homozygotes derived from inbreeding between germination and the adult phase.
\end{abstract}

Keywords: allozymes, fixation indices, outcrossing rates, Pinus leucodermis.

\section{Introduction}

Pinus leucodermis Ant. is a wind-pollinated coniferous species with a discontinuous and restricted distribution. Its range consists of small and disjunct populations located both in southern Italy and in the southern part of the Balkan peninsula. Little is known about the phylogenetic relationships between the populations from these two main portions of the species range and it is uncertain whether or not they all belong to the same species. Pinus leucodermis in Italy occurs in only four small groups of populations located in the South. Its previous distribution covered central and southern Italy (Avolio, 1986). Due to the restrictedness of its actual range and to the frequent occurrence of fires in these areas, it can be considered to be a highly endangered species whose genetic resources need to be analysed and conserved. Moreover, its ecological characteristics, such as great adaptability to extreme environmental conditions and great colonizing poten-

Correspondence address: M. Morgante, Istituto di Produzione Vegetale, Universitá di Udine, Via Fagagna 209, I-33100 Udine, Italy. tial (Brogi, 1960; Avolio, 1986) make it suitable for the reforestation of extensive dry areas in southern Italy.

As reproductive patterns in a population determine the genetic structure of the progeny generations, information on mating system and fertility variation in natural populations is needed to plan gene conservation programmes and to manage breeding populations (Muona, 1989). Moreover, determination of the outcrossing rates should be an integral part of any study of selection in plant populations (Ennos, 1981).

Coniferous species are known to be predominantly outbreeders (Stern \& Roche, 1974) and thus usually suffer from strong inbreeding depression (Franklin, 1970 ), but a variable and sometimes significant amount of selfing has been observed in natural populations of species of the genera Pinus, Picea and Pseudotsuga (Muona, 1989).

In this study we analyse the mating system of two natural populations of $P$. leucodermis in order to obtain an estimate of the outcrossing rate typical of the species, to find out whether there is between-population variation in the mating system and to examine to what extent filial and parental population structure 
reflect any inbreeding that might be revealed by the mating system analysis. An efficient multilocus model developed by Ritland \& El Kassaby (1985) was used for the mating system analysis, which also allows the estimation of pollen allele frequencies and outcrossing rates for individual trees.

\section{Materials and methods}

Current year cones were collected in September, 1985 from two populations of Pinus leucodermis located in southern Italy on Monte La Spina $\left(40^{\circ} 07^{\prime} \mathrm{N}, 15^{\circ} 56^{\prime} \mathrm{E}\right)$ at an altitude of $900 \mathrm{~m}$ and on Monte Pollino in locality Pollinello $\left(39^{\circ} 54^{\prime} \mathrm{N}, 16^{\circ} 11^{\prime} \mathrm{E}\right)$ at an altitude of $1800 \mathrm{~m}$. Twenty-five cones were taken from the upper part of the crown of each of 28 trees in La Spina population and 20 trees in Pollino population. The trees were spaced $50 \mathrm{~m}$ apart on average. Seeds were extracted using standard techniques, thus maintaining parental identity. They were air-dried to a moisture content of 7-8 per cent and stored in sealed containers at $2^{\circ} \mathrm{C}$ in the dark until needed.

Seed tissues were assayed for three enzyme systems, glutamate oxaloacetate transaminase (GOT), phosphoglucomutase (PGM) and shikimate dehydrogenase (SKDH). GOT was separated on an 11 per cent $w / v$ starch gel $\left(5 \mathrm{~h}\right.$ at $\left.30 \mathrm{~V} \mathrm{~cm}^{-1}\right)$ in a $0.3 \mathrm{M}$ boric acid$\mathrm{NaOH}, \mathrm{pH} 8.2$ buffer system (modified from Poulik, 1957). PGM and SKDH were separated on a 12 per cent $\mathrm{w} / \mathrm{v}$ starch gel $\left(6 \mathrm{~h}\right.$ at $\left.12 \mathrm{~mA} \mathrm{~cm}{ }^{-1}\right)$ in a $0.13 \mathrm{M}$ Tris-citrate, pH 7.0 buffer system (modified from Shaw \& Prasad, 1970). Enzyme staining procedures were taken from Cheliak \& Pitel (1984), with the following modification: MTT was used in place of NBT in SKDH staining. Four polymorphic loci were scored for the mating system analysis, namely GOT-A, GOT-C, PGM-A and SKDH-A: their Mendelian inheritance and lack of linkage have been previously verified by genetic segregation tests (M. Morgante \& G. G. Vendramin, in preparation). Between 25 and 30 dormant seeds were assayed, both for their embryo (diploid) and megagametophyte (haploid) genotypes. The megagametophyte genotype is genetically identical to that of the ovule so this allows the unambiguous ascertainment of the pollen contribution to the embryo even in progenies from heterozygous individuals.

Single locus and multilocus estimates of the proportion of progeny due to outcrossing $(t)$ in a population and of the pollen allele frequencies $(p)$ were computed using the maximum-likelihood procedure of Ritland \& El Kassaby (1985). This method is based on the mixed mating model (Fyfe \& Bailey, 1951) whose assumptions are described in Brown et al. (1985). The Ritland and El Kassaby procedure also gives estimates of out- crossing rates and pollen allele frequencies for individual trees. At the individual level the estimated outcrossing rate is the female one.

To assess the homogeneity of the pollen pool among maternal parent trees, the number of homozygous and heterozygous embryos borne by each female was entered into a $2 \times f$ contingency table (Brown et al., 1975), where $f$ is the number of homozygous females, and tested by a chi-square analysis. An estimate of the effective selfing caused by consanguineous matings was obtained by regression of the individual tree outcrossing pollen allele frequency on the additive value of the ovule genotype (Ritland, 1985). The additive values ( 0 , $0.5,1.0$ ) were assigned to the mother genotypes (aa, $\mathrm{Aa}, \mathrm{AA}$ ) respectively, where ' $\mathrm{A}$ ' is the most common allele. A minimum variance mean of the single locus regressions was computed. Single tree estimates of selffertilization rate, $s$, were also obtained for two trees carrying unique alleles in heterozygous state through the maximum likelihood procedure of Adams \& Joly (1980). The outcrossing rate, $t$, was then obtained as $1-s$.

Wright's (1965) fixation index $\left[F=1-H_{0} / H_{\mathrm{e}}\right]$ was estimated at each locus for the adult and progeny generations. The minimum variance mean of $F$ for each population was obtained after weighting the $F$ values at each locus by the inverse of their variance (Brown, 1979). The expected fixation index at inbreeding equilibrium, that is when all Hardy-Weinberg equilibrium assumptions apart from random mating are met, was computed as $F_{\mathrm{e}}=\left(1-t_{\mathrm{m}}\right) /\left(1+t_{\mathrm{m}}\right)$, where $t_{\mathrm{m}}$ is the multilocus outcrossing rate (Allard et al., 1968).

\section{Results and discussion}

The multilocus estimates of allele frequencies in the pollen are compared with the corresponding maternal parent frequencies for the two populations in Table 1. Differences between any pairs of allelic frequencies were checked for significance at the 5 per cent level by comparing bounds of confidence intervals. Only at the SKDH-A locus in population Pollinello was the difference significant. This could be due to differential pollen production among adult plants, which has been well documented in conifers (Müller-Starck \& Ziehe, 1984; Schoen \& Stewart, 1986; Muona, 1989), to selection at the gametophytic level [even though there is virtually no published evidence that this mechanism is active in gymnosperms (Apsit et al., 1989)], or to non-random pollination, which may result from restricted pollen movement.

The single- and multi-locus estimates of outcrossing rates are presented in Table 2. In La Spina the singlelocus $t$ values ranged from 72 to 77 per cent and in 
Table 1 Allelic frequencies and maternal and pollen-pool in the

\begin{tabular}{|c|c|c|c|c|c|}
\hline \multirow[b]{2}{*}{ Locus } & \multirow[b]{2}{*}{ Allele } & \multirow{2}{*}{$\begin{array}{l}\text { La Spina } \\
\text { Maternal }\end{array}$} & \multirow[b]{2}{*}{$\begin{array}{l}\text { Outcrossing } \\
\text { pollen* }\end{array}$} & \multicolumn{2}{|l|}{ Pollinello } \\
\hline & & & & Maternal & $\begin{array}{l}\text { Outcrossing } \\
\text { pollen* }\end{array}$ \\
\hline \multirow[t]{2}{*}{ GOT-A } & 1 & 0.000 & 0.000 & $0.175 \pm 0.118$ & $0.063 \pm 0.024$ \\
\hline & 2 & 1.000 & 1.000 & $0.825 \pm 0.118$ & $0.937 \pm 0.024$ \\
\hline \multirow[t]{4}{*}{ GOT-C } & 1 & 0.000 & 0.000 & $0.050 \pm 0.068$ & $0.017 \pm 0.012$ \\
\hline & 2 & $0.893 \pm 0.088$ & $0.861 \pm 0.029$ & $0.950 \pm 0.068$ & $0.983 \pm 0.012$ \\
\hline & 3 & $0.036 \pm 0.051$ & $0.057 \pm 0.020$ & 0.000 & 0.000 \\
\hline & 4 & $0.071 \pm 0.071$ & $0.083 \pm 0.024$ & 0.000 & 0.000 \\
\hline \multirow[t]{2}{*}{ PGM-A } & 1 & $0.179 \pm 0.100$ & $0.242 \pm 0.039$ & $0.200 \pm 0.124$ & $0.093 \pm 0.027$ \\
\hline & 2 & $0.821 \pm 0.100$ & $0.758 \pm 0.039$ & $0.800 \pm 0.124$ & $0.907 \pm 0.027$ \\
\hline \multirow[t]{2}{*}{ SKDH-A } & 1 & $0.750 \pm 0.118$ & $0.836 \pm 0.035$ & $0.725 \pm 0.138$ & $0.912 \pm 0.029$ \\
\hline & 2 & $0.250 \pm 0.118$ & $0.164 \pm 0.035$ & $0.275 \pm 0.138$ & $0.088 \pm 0.029$ \\
\hline
\end{tabular}

*Based upon multi-locus estimate.

Table 2 Single locus $\left(\hat{t}_{\mathrm{i}}\right)$ and multilocus $\left(\hat{t}_{\mathrm{m}}\right)$ estimates of outcrossing rate and singlelocus minimum variance mean $(\bar{t})$ in the two populations (standard errors in parentheses)

\begin{tabular}{|c|c|c|c|c|}
\hline \multirow[b]{2}{*}{ Locus } & \multicolumn{2}{|l|}{ La Spina } & \multicolumn{2}{|l|}{ Pollinello } \\
\hline & $\begin{array}{l}\text { Number of } \\
\text { seeds analysed }\end{array}$ & $\hat{t}_{\mathrm{i}}$ & $\begin{array}{l}\text { Number of } \\
\text { seeds analysed }\end{array}$ & $\hat{t}_{\mathrm{i}}$ \\
\hline GOT-A & - & - & 596 & $0.857(0.052)$ \\
\hline GOT-C & 739 & $0.771(0.064)$ & 596 & $0.617(0.104)$ \\
\hline PGM-A & 739 & $0.717(0.061)$ & 595 & $0.882(0.054)$ \\
\hline SKDH-A & 679 & $0.723(0.055)$ & 594 & $0.843(0.046)$ \\
\hline $\bar{t}$ & & $0.735(0.034)$ & & $0.841(0.028)$ \\
\hline$\hat{t}_{\mathrm{m}}$ & 741 & $0.765(0.032)$ & 600 & $0.840(0.029)$ \\
\hline $\begin{array}{l}\text { Heterogeneity* } \\
\text { Chi-square of } \hat{t}_{\mathrm{i}}\end{array}$ & & $\chi_{2}^{2}=0.45 \mathrm{~ns}$ & & $\chi_{3}^{2}=5.31 \mathrm{~ns}$ \\
\hline
\end{tabular}

*The heterogeneity test of $t$ is given by $\chi_{k-1}^{2}=\Sigma I_{\mathrm{i}}\left(\hat{t}_{\mathrm{i}}-\hat{t}\right)^{2}$, with $k-1$ d.f.; the information measure $I_{\mathrm{i}}$ is the inverse of the variance for the $i$ th estimate of $t$ (Kahler et al., 1984).

Pollinello from 62 to 88 per cent. The chi-square test did not detect any significant heterogeneity between the single locus estimates in any of the two populations. All the single locus values are significantly higher in Pollinello than in La Spina, with the exception of the GOT-C locus, at which the estimate is much lower. Its standard error is, however, twice as large as those at the other loci. This difference could therefore be attributed to statistical inefficiency of the estimator due to violation of the mixed-mating model assumptions. Single locus estimates of outcrossing rate are known to be lowered by any form of inbreeding in addition to selfing, such as mating among relatives (Shaw \& Allard,
1982) due to family substructuring of the populations. Multilocus estimates, on the contrary, are much more robust to any violation of the mixed-mating model assumptions. The comparison of single- and multilocus measures therefore gives information on the amount of inbreeding other than selfing (Ritland \& Jain, 1981). The multilocus estimate of $t$ in La Spina is 76.5 per cent, a lower value than that of Pollinello, which is 84.0 per cent. The negligible differences between the single-locus minimum variance mean and the multilocus estimates observed in Pollinello and $\mathrm{La}$ Spina populations indicate that most or all apparent selfing in the two stands is caused by actual self- 
fertilization and is not the result of consanguineous matings. However, Ritland \& Jain (1981) have demonstrated, using simulation studies, that multilocus estimates of the outcrossing rate can also be biased downwards when a small number of loci is used. As this was the case in our study we used two other methods in order to determine whether and to what extent our outcrossing estimates have been lowered by violations of the mixed-mating model.

Firstly we tested the hypothesis of homogeneity in pollen pool allele frequencies over the maternal trees by means of a contingency chi-square test between progenies of homozygous individuals (Table 3 ). Local heterogeneity in the pollen pool may arise from spatial substructuring of the population and restricted pollen dispersal and therefore can also be related to consanguineous matings, or from tree to tree variation in the outcrossing rate (Brown et al., 1975). In one single case, at the PGM-A locus in Pollinello population, the null hypothesis of homogeneity of pollen allele frequencies was rejected at the 5 per cent level of significance. If variation in the individual $t \mathrm{~s}$ was the cause, then all the loci should be affected in the same way (Knowles et al., 1987). As this was not the case, we can reject this interpretation. If family substructuring was the cause, there should be a correlation between the presence of the heterogeneity and the deviation from random mating at each locus. At the PGM-A locus, however, we had the highest outcrossing rate estimate (Table 2). We can therefore conclude that spatial heterogeneity of the pollen pool allele frequencies does not contribute significantly to the lowering of our outcrossing rate estimates.

In the second test we used the regression of the pollen allele frequencies (obtained from the joint estimation of $t$ and $p$ for individual trees) on the additive values of the ovule genotype in order to obtain a direct estimate of the selfing caused by mating among relatives. According to Ritland (1985) the regression line has an expected slope equal to the amount of estimated selfing caused by consanguineous matings.

Table 3 Chi-square test for the heterogeneity of pollen pool allele frequencies across female parent trees (degrees of freedom in parentheses)

\begin{tabular}{|c|c|c|}
\hline Locus & La Spina & Pollinello \\
\hline GOT-A & - & $4.63(12) \mathrm{ns}$ \\
\hline GOT-C & $23.21(21) \mathrm{ns}$ & $14.66(17) \mathrm{ns}$ \\
\hline PGM-A & $12.98(18) \mathrm{ns}$ & $23.81(11)^{*}$ \\
\hline SKDH-A & $17.05(13) \mathrm{ns}$ & $13.99(9) \mathrm{ns}$ \\
\hline
\end{tabular}

*Significant at the 5 per cent level.
The regression (Table 4) had a non-significant average coefficient for La Spina population, and a highly significant one for Pollinello. If we consider, however, the single locus coefficients, we can observe that the significance of the mean value is merely due to the GOT-C locus, which is also the one with the lowest outcrossing rate estimate and the highest standard error. We can therefore consider mating among relatives as the most probable cause of the bias in the GOT-C locus estimate of $t$. The regression of pollen allele frequencies on maternal genotypes also reveals that, with the exception of the above mentioned locus, mating among relatives is not the cause of our low $t$ estimates. They therefore reflect a significant amount of true self-fertilization.

A further confirmation of the presence of a significant amount of selfing in Pinus leucodermis comes from the estimates of outcrossing rate obtained from trees that carry a unique allele in the heterozygous state (Table 5). The estimate of the mother tree from $\mathrm{La}$ Spina was lower than the population multilocus value. In the other tree, which belongs to a third population, Valle Torta, located close to Pollinello, but at a lower altitude, we had a still lower outcrossing estimate. The same estimation method gave much higher outcrossing rates in Pinus taeda (Adams \& Joly, 1980) and in Pinus sylvestris (Müller, 1977; Rudin et al., 1986).

As far as the multilocus estimates of $t$ and $p$ obtained for individual trees are concerned, it must be

Table 4 Regression of pollen allele frequencies on maternal genotype and minimum variance mean over loci $(\hat{t}$ and $\hat{p}$ jointly estimated)

\begin{tabular}{lcc}
\hline Locus & La Spina & Pollinello \\
\hline GOT-A & - & 0.003 \\
GOT-C & -0.066 & $0.314^{* *}$ \\
PGM-A & 0.116 & -0.055 \\
SKDH-A & -0.001 & 0.017 \\
Sample size & 22 & 18 \\
Mean & 0.016 & $0.082^{* *}$ \\
\hline
\end{tabular}

** Significant at the 1 per cent level.

Table 5 Outcrossing rates obtained from trees carrying a unique allele in heterozygous state

\begin{tabular}{lcll}
\hline Locus & Tree number & Population & $\hat{t}(\text { S.E. })^{*}$ \\
\hline 6PGD-A & 4 & La Spina & $0.689(0.071)$ \\
IDH-B & 14 & Valle Torta & $0.527(0.115)$ \\
\hline
\end{tabular}

*Standard error from Adams \& Joly (1980). 
remembered that the $t$ values estimate the female outcrossing rates of single trees, which need not equal the male outcrossing estimates (Horovitz \& Harding, 1972; Gregorius et al., 1987). The individual $t$ values have been computed in two different ways, (i) keeping $p$ constant and equal to the population estimate and (ii) allowing $p$ to vary between families. The averages of the individual $t$ obtained with both methods (Table 6) were higher than the population multilocus estimates in both populations. This observation is in accordance with the results of Ritland \& El Kassaby (1985) in Douglas fir. The range of among-tree variation was

Table 6 Distribution of estimates for female outcrossing rate of individual trees, for intervals with midpoints (L.S. $=\mathrm{La}$ Spina; Poll. $=$ Pollinello)

\begin{tabular}{lccccc}
\hline & \multicolumn{2}{l}{ Only $\hat{t}(\%)$} & & \multicolumn{2}{l}{ Joint $\hat{t}, \hat{p}(\%)$} \\
\cline { 2 - 3 } \cline { 5 - 6 } Midpoint & L.S. & Poll. & & L.S. & Poll. \\
\hline$\hat{t}$ & & & & \\
0.1 & 0 & 0 & & 0 & 0 \\
0.3 & 8 & 0 & & 5 & 0 \\
0.5 & 16 & 5 & & 27 & 11 \\
0.7 & 20 & 25 & & 18 & 28 \\
0.9 & 32 & 50 & 32 & 22 \\
1.1 & 12 & 10 & & 14 & 11 \\
1.3 & 12 & 10 & & 5 & 17 \\
1.5 & 0 & 0 & & 0 & 11 \\
1.7 & 0 & 0 & & 0 & 0 \\
1.9 & 0 & 0 & & 0 & 0 \\
Sample size & 25 & 20 & & 22 & 18 \\
Mean $\hat{t}$ & 0.815 & 0.890 & 0.785 & 0.947 \\
\hline
\end{tabular}

quite wide but smaller than that observed in Douglas fir. The variation is not due to true biological variation between trees in individual outcrossing rates, but rather to sampling variance, because the observed among-tree variance per individual was nearly equal to the one expected when $t$ has no true variation among trees, as determined by inversion of the expected information matrix. The individual tree estimates of $t$, which exceed 1 , may not be biologically realistic, unless negative assortative mating is involved (Cheliak et al., 1983). In our case they are probably due to sampling error, which is at least partly attributable to the small family size (about 30 progeny per mother tree). They have nevertheless to be taken into account, if an unbiased estimate of $\hat{t}$ is to be obtained (Brown et al., 1985).

The expected fixation index at inbreeding equilibrium (Allard et al., 1968) was computed on the basis of the multi-locus estimate of outcrossing rate in the two populations. The expected $F$ values were compared with the minimum variance mean $F$ of progeny and parents (Table 7). The $t$-test was significant for the parental generation but not for the filial one. This occurs because in both populations there is a considerable difference in the genotypic distribution between the two life-cycle phases. The parental generation always shows a much lower fixation index than the filial. If a similar bias towards inbreeding existed in the seed crop that produced the sampled parental trees, a significant part of the reduction in homozygosity between the two phases could be due to selection against inbreds. This is a phenomenon which has often been reported in conifers, which usually show a noticeable inbreeding and particularly selfing depression (Sorensen \& Miles, 1982; Sorensen, 1982; Griffin \&

Table 7 Fixation indices (S.E. in parentheses after Rasmussen, 1964) for the parental and progeny generations in the two populations

\begin{tabular}{|c|c|c|c|c|}
\hline \multirow[b]{3}{*}{ Locus } & \multicolumn{4}{|c|}{ Population } \\
\hline & \multicolumn{2}{|c|}{ La Spina } & \multicolumn{2}{|c|}{ Pollinello } \\
\hline & Parents & Progeny & Parents & Progeny \\
\hline GOT-A & - & - & $-0.212(0.079)$ & $0.118(0.050)$ \\
\hline GOT-C & $-0.091(0.107)$ & $0.028(0.040)$ & $-0.053(0.032)$ & $0.340(0.087)$ \\
\hline PGM-A & $0.026(0.195)$ & $0.145(0.041)$ & $-0.250(0.086)$ & $0.053(0.045)$ \\
\hline SKD-A & $-0.128(0.173)$ & $0.242(0.043)$ & $-0.129(0.203)$ & $0.076(0.044)$ \\
\hline $\begin{array}{l}F(\text { minimum } \\
\text { variance mean })\end{array}$ & $-0.079(0.083)$ & $0.133(0.024)$ & $-0.095(0.028)$ & $0.102(0.025)$ \\
\hline$F_{\mathrm{e}}$ & \multicolumn{2}{|c|}{0.133} & \multicolumn{2}{|c|}{0.087} \\
\hline$t$-test for $F=F_{\mathrm{e}}$ & $P<0.05$ & ns & $P<0.01$ & ns \\
\hline
\end{tabular}


Lindgren, 1985) attributed to the action of recessive lethal and deleterious alleles. Our estimate of the proportion of selfed progeny in Pinus leucodermis was obtained on dormant seeds which were scored prior to germination. If selection against inbred progeny acts during germination, then our selfing rate estimates are likely to be lower than those based on the analysis of germinating embryos, which are normally used in studies of conifer mating systems. The same seed lots which we utilized for the mating system analysis were employed by Borghetti et al. (1989) for a study on the germination ecology of Pinus leucodermis. Seeds from the La Spina population had a significantly higher germination rate than those from Pollinello, although seeds from $\mathrm{La}$ Spina are selfed to a greater extent than those from Pollinello (Table 2). These data seem to indicate that strong selection does not act against selfed progeny during germination in this species. Vaquero et al. (1989) report a similar observation in rye, whilst a positive correlation between germination and outcrossing rates was observed in Robinia pseudoacacia (Surles et al., 1990).

The analysis of the mating system of Pinus leucodermis has shown that this species is distinguished by a significant and possibly variable level of true selffertilization. This level is higher than that usually found in coniferous species, which tend to have very high outcrossing rates (Muona, 1989). Selfing levels similar to those of Pinus leucodermis have only been reported in Pinus radiata (G. F. Moran, J. C. Bell and O. Muona, unpublished results) and Larix laricina (Knowles et al., 1987). In the last species a positive relationship was found between stand density and outcrossing rate. In the only high density population the outcrossing rate was higher than in the low density situations $(0.91$ versus an average of 0.74). La Spina and Pollinello populations are both rather high density stands, so that stand density is unlikely to be responsible for the low outcrossing estimates obtained. It has to be stressed, however, that the relationship between stand density and outcrossing rate has not been observed in Jeffrey pine (Furnier \& Adams, 1986) nor in Douglas fir (Neale \& Adams, 1985).

Differences in self-fertility due to a different number of lethal equivalents could explain the variability in outcrossing rate among the two analysed populations. This hypothesis, of course, needs to be tested through the comparative analysis of progenies from controlled self- and cross-pollinations.

The presence of a significant level of self-fertilization in Pinus leucodermis has important implications for seed production, as it seems that there is a strong selection against homozygotes derived from inbreeding, acting between seed production and the adult phase. Natural stands managed for seed production should hence be chosen among those with the highest proportion of outcrossed progeny. Furthermore, if open-pollinated families are to be used in order to obtain estimates of genetic parameters such as heritability and genetic gain, the level of inbreeding should be accounted for in the computations because a basic assumption of heritability estimation is that openpollinated progenies are not selfed to a significant level (Namkoong, 1966).

\section{Acknowledgements}

The authors are indebted to $\mathrm{H}$. R. Gregorius, K. Kärkäinnen, O. Muona and M. Ziehe for their critical comments and helpful suggestions which greatly improved an earlier version of the manuscript. The authors wish to thank F. Piccini for technical assistance.

\section{References}

ADAMS, w. T. AND JOLY, R. J. 1980. Allozymes studies in loblolly pine seed orchards: clonal variation and frequency of progeny due to self-fertilization. Silvae Genet., 29, 1-4.

ALLARD, R. W., JAIN, S. K. AND WORKMAN, P. L. 1968. The genetics of inbreeding populations. Adv. Genet., 14, 55-131.

APSIT, V. J., NAKAMURA, R. R. AND WHEELER, N. C. 1989. Differential male reproductive success in Douglas fir. Theor. Appl. Genet., 77, 681-684.

AVolio, s. 1986. Il pino loricato (Pinus leucodermis Ant.). Ann. Ist. Sper. Selv., XVII, 79-153.

BORGHETTI, M., VENDRAMIN, G. G., GIANNINI, R. AND SCHETTINO, A. 1989. Effects of stratification, temperature and light on germination of Pinus leucodermis. Acta Oecologica Oecol. Plant., 10, 45-56.

BROGI, s. 1960. Il pino loricato (Pinus heldreichii Christ. var. leucodermis Ant.) in Calabria e sua possibilità di diffusione. It. For. Mont., 108, 211-235.

BROWN, A. H. D. 1979. Enzyme polymorphism in plant populations. Theor. Popul. Biol., 15, 1-42.

BROWN, A. H. D., MATHESON, A. C. AND ELDRIDGE, K. G. 1975. Estimation of the mating system of Eucalyptus obliqua L'Herit. by using allozyme polymorphisms. Aust. J. Bot., 23, 931-949.

BROWN, A. H. D., BARRETT, S. C. H. AND MORAN, G. F. 1985. Mating system estimation in forest trees: models, methods and meanings. In: Gregorius, H. R. (ed.), Population Genetics in Forestry. Lecture Notes in Biomathematics, 60 , Springer-Verlag, Berlin, pp. 32-49.

CHELIAK, W. M. AND PITEL, J. A. 1984. Techniques for starch gel electrophoresis of enzymes from forest tree species. Petawawa National Forestry Institute, Canadian Forestry Service, Information Report PI-X-42.

CHELIAK, W. M., MORGAN, K., STROBECK, C., YEH, F. C. H. AND DANCIK, B. P. 1983. Estimation of mating system parameters in plant populations using the EM algorithm. Theor. Appl. Genet., 65, 157-161. 
ENNOS, R. A. 1981. Quantitative studies of the mating system in two sympatric species of Ipomoea (Convolvulaceae). Genetica, 57, 93-98.

FRANKLIN, E. C. 1970. A survey of mutant forms and inbreeding depression in species of the family Pinaceae. USDA For. Serv. Res. Pap., SE-61.

FURNIER, G. R. AND ADAMS, w. T. 1986. Mating system in natural populations of Jeffrey pine. Am. J. Bot., 73, 1002-1008.

FYFE, J. L. AND BAILEY, N. T. J. 1951. Plant breeding studies in leguminous forage crops. I. Natural crossbreeding in winter beans. J. Agric. Sci, 41, 371-378.

GREGORIUS, H. R., ZIEHE, M. AND ROSS, M. D. 1987. Selection caused by self-fertilization. I. Four measures of selffertilization and their effects on fitness. Theor. Popul. Biol., 31, 91-115.

GRIFFIN, A. R. AND LINDGREN, D. 1985. Effect of inbreeding on production of filled seed in Pinus radiata - experimental results and a model of gene action. Theor. Appl. Genet., 71, 334-343.

HOROVITZ, A. AND HARDING, J. 1972. The concept of male outcrossing in hermaphroditic higher plants. Heredity, 29, 223-236.

KAHLER, A. L., GARDNER, C. O. AND ALlard, R. w. 1984. Nonrandom mating in experimental populations of maize. Crop Sci., 24, 350-354.

KNOWLES, P., FURNIER, G. R., ALEKSIUK, M. A. AND PERRY, D. J. 1987. Significant levels of self-fertilization in natural populations of tamarack. Can. J. Bot., 65, 1087-1091.

MÚLLER, G. 1977. Untersuchungen über die natürliche Selbstbefrüchtung in Beständen der Fichte [Picea abies (1.) Karst.] und Kiefer (Pinus sylvestris L.). Silvae Genet., 26, 207-217.

MULLER-STARCK, G. AND ZIEHE, M. 1984. Reproductive systems in conifer seed orchards. 3. Female and male fitnesses of individual clones realized in seeds of Pinus sylvestris L. Theor. Appl. Genet., 69, 173-177.

MUONA, o. 1989. Population genetics in forest tree improvement. In: Brown, A. H. D., Clegg, M. T., Kahler, A. L. and Weir, B. S. (eds), Plant Population Genetics, Breeding and Genetic Resources. Sinauer, Sunderland, pp. 282-298.

NAMKOONG, G. 1966. Inbreeding effects on estimation of genetic additive variance. For. Sci., 12, 8-13.

NEALE, D. B. AND ADAMS, w. T. 1985. The mating system in natural and shelterwood stands of Douglas-fir. Theor. Appl. Genet., 71, 201-207.
POULIK, M. D. 1957. Starch gel electrophoresis in a discontinuous system of buffers. Nature, 180, 1477-1478.

RASMUSSEN, D. I. 1964. Blood group polymorphism and inbreeding in natural populations of deer mouse, Peromyscus maniculatus. Evolution, 18, 219-229.

RITLAND, K. 1985. The genetic mating structure of subdivided populations. 1. Open-mating model. Theor. Popul. Biol., 27, 51-74.

RITLAND, K. AND EL-KASSABY, Y. A. 1985. The nature of inbreeding in a seed orchard of Douglas-fir as shown by an efficient multilocus model. Theor. Appl. Genet., 71, 375-384.

RITLAND, K. AND JAIN, S. K. 1981. A model for the estimation of outcrossing rate and gene frequencies using $n$ independent loci. Heredity, 47, 35-52.

RUDIN, D., MUONA, O. AND YAZDANI, R. 1986. Comparison of the mating system of Pinus sylvestris in natural stands and seed orchards. Hereditas, 104, 15-19.

SCHOEN, D. J. AND STEWART, S. C. 1986. Variation in male reproductive investment and male reproductive success in white spruce. Evolution, 40, 1109-1120.

SHAW, C. R. AND PRASAD, R. 1970. Starch gel electrophoresis. A compilation of recipes. Biochem. Genet., 4, 297-320.

SHAW, D. V. AND ALLARD, R. W. 1982. Estimation of outcrossing rates in Douglas-fir using isozyme markers. Theor. Appl. Genet., 62, 113-120.

SORENSEN, F. C. 1982. The roles of polyembryony and embryo viability in the genetic system of conifers. Evolution, 36, $725-733$.

SORENSEN, F. C. AND MILES, R. S. 1982. Inbreeding depression in height, height growth, and survival of Douglas-fir, ponderosa pine and noble fir to 10 years of age. For. Sci., 28, 283-292.

STERN, K. AND ROCHE, L. 1974. Genetics of Forest Ecosystems. Springer-Verlag, Berlin.

SURLES, S. E., HAMRICK, J. L. AND BONGARTEN, B. C. 1990. Mating systems in open-pollinated families of black locust (Robinia pseudoacacia) Silvae Genet., 39, 35-40.

VAQUERO, F., VENCES, F. J., GARCIA, P., RAMIREZ, L. AND PEREZ DE LA VEGA, M. 1989. Mating system in rye: variability in relation to the population and plant density. Heredity, 62, 17-26.

WRIGHT, s. 1965. The interpretation of population structure by $F$-statistics with special regard to systems of mating. Evolution, 9, 395-420. 